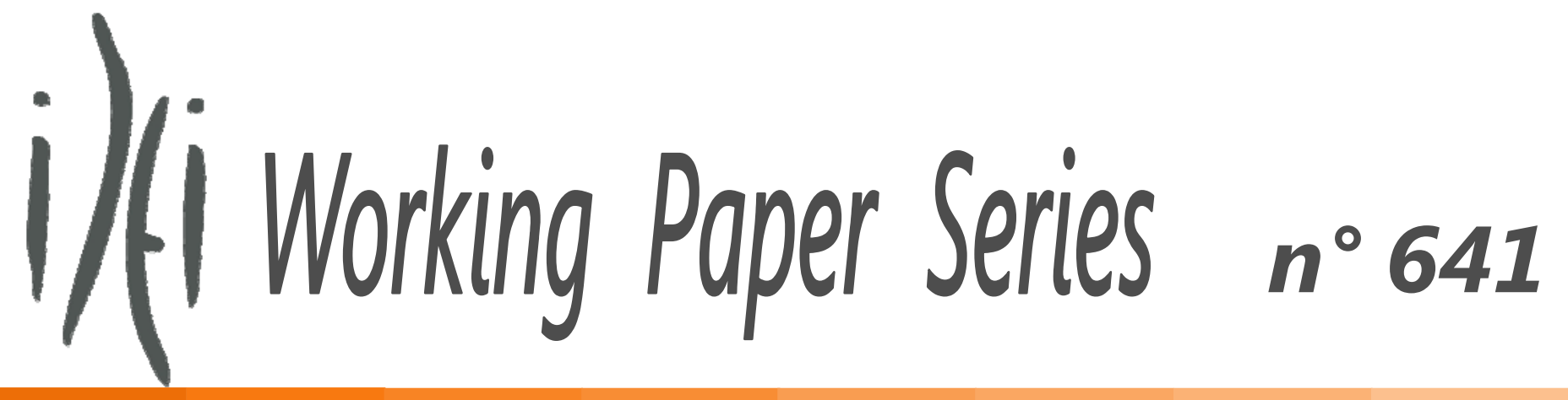

October, 2010

\title{
"Does the EU Sugar Policy Reform Increase added Sugar Consumption? An Empirical Evidence on the Soft Drink Market"
}

\section{Céline BONNET and Vincent RÉQUILLART}




\title{
Does the EU sugar policy reform increase added sugar consumption? An empirical evidence on the soft drink market.
}

\author{
Céline Bonnet* and Vincent Requillart ${ }^{\dagger}$
}

October $2010^{\ddagger}$

\begin{abstract}
National Health authorities recommend a decrease in the consumption of 'added' sugar. At the same moment, a reform of the Common Organisation of the Sugar Market will lead to a decrease by more than $30 \%$ of the sugar price in the EU. Using French data on the soft drinks purchases, this paper investigates the impact of this reform on the consumption of sugar sweetened beverages and on added sugar consumption. The soft drink market is composed of highly differentiated products with different sugar content. Hence the reform of the EU sugar policy leads to a decrease in regular soft drink prices by more than $3 \%$ in average and varies from $1.7 \%$ to $6.5 \%$ according to the brand. To assess substitution within the food category of sugar sweetened beverages, we use a structural econometric model, the random-coefficients logit model. Our model also takes into account observed and unobserved heterogeneity in the consumers' behavior and then allows to estimate the impact of the sugar price decrease on the soft drink consumption according to the type of consumers. Results suggest that price changes would lead to an increase in market shares of regular products by $7.5 \%$ and a decrease in market share of diet products by $3.5 \%$. On the whole, it would rise the consumption of regular soft drinks by more that 1 liter per year and per person and the consumption of added sugar by 124 grams per year and per person. Moreover, the reform leads to substitution between brands at the benefit of products with the highest sugar content. The increase in per person consumption is larger in households composed of overweight and obese individuals.
\end{abstract}

JEL codes: D12, I18, Q18.

Key words: differentiated products, soft drinks, sugar CMO, random coefficients logit model.

\footnotetext{
${ }^{*}$ Toulouse School of Economics (INRA, GREMAQ), 21 Allée de Brienne, F-31000 Toulouse France, Tel: +33 (0)5 6112 85 91, cbonnet@toulouse.inra.fr

${ }^{\dagger}$ Toulouse School of Economics (INRA, GREMAQ; IDEI), 21 Allée de Brienne, F-31000 Toulouse France, Tel: +33 (0)5 611286 07, vincent.requillart@toulouse.inra.fr

${ }^{\ddagger}$ We thank Marine Spiteri for helping us starting the project. We thank participants to the WEHE seminar in Lausanne and the EAAE-AAEA seminar in Freising for their comments. Any remaining errors are ours.
} 


\section{Introduction}

In a recent paper, Schroeter et al. (2008) concluded that 'a relative efficient intervention (to combat obesity in the US) is to apply a tax on caloric soft drinks'. An on-going reform of the sugar policy in the $\mathrm{EU}$ is going to reduce the $\mathrm{EU}$ price of caloric sweeteners by $36 \%$. As sugar is the main variable input of the soft drink industry, the reform is the exact opposite of this recommendation. In this paper, we investigate the impact of the EU sugar policy reform on soft drink consumption and added sugar consumption, and discuss its likely effects on obesity.

In almost every developped countries, obesity rates have significantly increased over the last decades (Sassi et al., 2009). This is mainly due to a decrease in the price of food calories combined with an increase in the cost of burning calories (Cutler et al., 2003). These price changes favoured an increase in calories intake and a decrease in calories utilisation which finally led to a weight increase. ${ }^{1}$ Because obesity is now thought as a major public health problem, public actions are developped in order to combat obesity rise. Till now, they mainly rely on information campaigns while pricing policies are discussed but are rarely put in place (Mazzochi et al., 2009). Because food prices do depend on agricultural product prices, there is also a debate about the role of agricultural policies on the rise in obesity. For example, Lloyd-William et al. (2008) concluded that the EU agricultural policy led to a significant increase in cardiovascular mortality as the policy favoured the consumption of saturated fats. However, there exist some controversies about the impact of agricultural policies certainly because distorsions created by agricultural policies vary significantly across products (see for example Alston et al., 2006).

Over the last 20 years, sugar price in the European Union (EU) was well above the world market price. A combination of price floor, import duties, export subsidies and quotas were used to sustain the domestic price (European Commission, 2004). Moreover due to restrictive quota, High Fructose Corn Syrup (HFCS) did not substitute for sugar in the EU as it was the case in the US where the sugar policy also maintained high prices for sugar. ${ }^{2}$ Thus in the EU the price of caloric sweeteners were high

\footnotetext{
${ }^{1}$ Other elements might explain the rise in obesity in the population such as a higher share of olders in the population but it seems that the main ingredient is the change in prices and cost of using calories.

${ }^{2}$ For an analysis of competition between sugar and HFCS in the EU, see Cooper et al. (1995). For an analysis of the USsweetener market, see Beghin et al. (2003).
} 
as compared to other countries. The past sugar policy did not favoured sugar consumption in the EU. However, in February 2006 a reform of the EU sugar policy was agreed (Union Européenne, 2006). The reform will lead to a significant decrease in the EU sugar price. The reference price, which roughly acts as a floor price, will be reduced by $36 \%$ over a 4 -year period starting in $2006 .{ }^{3}$ This reform is at odds of what would be recommended by nutritionnists or public health authorities. For example, one of the objective of the french 'Programme National Nutrition Santé' is to decrease by $25 \%$ the consumption of added sugar (Ministère de la Santé et des Solidarités, 2006).

Therefore, while the health policy has set an ambitious objective of reduction of added sugar intake in the french population, the reform of the sugar policy in the EU will lead to a significant decrease in the price of sugar. If transmitted to the price of final sweet products, the decrease in the sugar price might induce an increase in their consumption which could be detrimental for health. Thus, some empirical studies have focused on the relationship between food consumption and obesity and suggest that policies which increase the price of calories may provide useful tools to reduce caloric intake and therefore to reduce the prevalence of obesity (Jacobson and Brownell, 2000; Ransley et al., 2003; Schroeter et al., 2008; Bonnet et al., 2009).

In the food and health economics literature most analysis of tax policies use a system of demand equations on broad food categories. Each equation specifies the demand for a food category as a function of its own price, the price of other food categories, and other variables (Chouinard et al., 2007; Smed et al., 2007; Leicester and Windmeijer, 2004, Marshall, 2000; Allais et al., 2010; Etile, 2010; Bonnet et al., 2009). These models do not allow for substitutions within a food category while it is composed of highly differentiated products with different nutrient content that consumers substitute. ${ }^{4}$ Estimating demand for differentiated products with common demand models is nontrivial given the large number of parameters

\footnotetext{
${ }^{3}$ The reference price for white sugar is $631.9 € / \mathrm{t}$ from 1 July 2006 to 30 September 2008. It is $541.5 € / \mathrm{t}$ from 1 October 2008 to 30 September 2009 and it is $404.4 € / \mathrm{t}$ after 1 October 2009. As a comparison, in 2007, the average world market price of sugar was about $310 € / \mathrm{t}$. In April 2010, the average price of sugar in the EU was $477 € / \mathrm{t}$ while it was $636 € / \mathrm{t}$ in 2006 which represents a $25 \%$ decrease. (http://ec.europa.eu/agriculture/minco/manco/cmo/index.htm)

${ }^{4}$ Whatever the coverage of the study, from the analysis of a complete demand system as in Bonnet et al. (2009) or Allais et al. (2010) to the analysis of a more specific market as in Chouinard et al. 2007 on dairy products where they distinguish about 10 dairy products distinguishing between skimmed milk and non-skimmed milk, products within a category are assumed to be identical.
} 
to be estimated. Moreover, these models do not allow for heterogeneity in consumer tastes and it is likely that preferences for products are not homogeneous across consumers. To tackle both problems, we propose to estimate a random coefficients logit model that solves the problem of the number of parameters to be estimated by projecting products onto a space of characteristics (McFadden, 1973) and allows to introduce heterogeneous preferences of consumers. Futhermore, the estimation method developped by Berry et al. (1995) and Nevo (2000) allows to solve the endogeneity problem of prices. Indeed, prices are correlated with the error term of demand equations as unobserved characteristics included in the error term might be correlated with prices (e.g. advertising, promotions).

In this paper, we intend to assess the impact of the sugar price decrease on the Soft Drink consumption in France taking into account the heterogeneity of supply in the sugar-sweetened beverages (SSBs) industry. We choose this industry for three reasons. First, there is strong evidence that consumption of SSBs is a contributor to the 'epidemic' of obesity (Harnack et al., 1999). Thus, in a systematic review of the impact of SSBs intake on weight gain, Malik et al. (2006) concluded by the following: "the weight of epidemiologic and experimental evidence indicates that a greater consumption of SSBs is associated with weight gain and obesity. Although more research is needed, sufficient evidence exists for public health strategies to discourage consumption of sugary drinks as part of a healthy lifestyle". ${ }^{5}$ Any decrease in the price of SSBs would thus leads to an increase in their consumption which might have a negative impact on health. Second, according to AFSSA (2009), SSBs are the main contributor in caloric sweeteners for children (19.1\%) and the third one for adults (13.3\%). Third, sugar is an important input in this industry as the sugar content of SSBs ranges from $6 \%$ to $11 \%$. Moreover, sugar costs range from 7 to $24 \%$ of the final price of SSBs. The anticipated $36 \%$ decrease in the price of sugar might have significant impact on SSBs prices.

This paper uses a structural econometric model that allows to account for the heterogeneity in consumers' preferences with respect to the different brands available and in particular according to demo-

\footnotetext{
${ }^{5}$ One possible explanation of the physiological mechanism involved is the following: 'consumption of sugar-sweetened drinks could lead to obesity because of imprecise and incomplete compensation for energy consumed in liquid form' (Ludwig et al., 2001; see also Malik et al., 2006). There is some controversy whether HFCS is more detrimental than sugar (see for example Melanson et al., 2007). However this does not significantly change the general conclusion that SSBs are a major contributor to the epidemic of obesity.
} 
graphic characteristics such as the proportion of overweight and obese individuals in a household. Hence, we will be able to account for different responses to price changes according to obesity status of households. We will also be able to distinguish different price changes as the sugar content of brands differs. Our results suggest that the larger the proportion of overweight and obese individuals in a household, the less sensitive to change in prices consumers are. This implies that a decrease of SSBs prices would have a larger impact on the percent change in consumption of households with 'thin' individuals. However, the consumption of households with obese people might increase more due to their initial higher consumption. The reform of the EU sugar policy might lead to a decrease in regular SSBs prices by 3.4\% in average and from $1.7 \%$ to $6.5 \%$ depending on the brand. The sugar price decrease would lead to an increase of market shares by $7.5 \%$ for regular products and a decrease by $3.5 \%$ for diet products. This would imply an increase in the regular soft drink consumption of 1.3 liter per person and per year and an increase in added sugar consumption of 124 grams per year and per person. Depending on the 'weight status' of the household, the average increase in per person consumption varies from 1.1 to 1.4 liters of Soft Drinks and from 116 to 141 grams of added sugar. The analysis also shows that the brands with the highest sugar content increase their market share in a larger proportion. The reform thus increases soft drink consumption but also induces a shift in favour of the products with the highest sugar content. This latter result fully justifies the use of a demand model with differentiated products to capture substitutions between products with different sugar content.

The paper is organized as follows. Section 2 presents the main characteristics of the soft drinks market. Section 3 presents the data and descriptive statistics about soft drink consumption. Section 4 describes the demand model that allows to assess own and cross-price elasticities. In section 5 we discuss demand results as well as the impact of the sugar policy reform. Finally we conclude in section 6 .

\section{The Soft Drinks market}

Soft drinks represent about $11 \%$ of the total beverages consumption in France which include mineral water, alcohol, coffee, tea, drinking milk as well as fruit juices (Canadean, 2004). In average, soft 
drinks consumption increased by $32 \%$ from 1994 to $2004 .{ }^{6}$ Nevertheless, the per capita consumption in France (42.5 liters per year) remains small as compared to the per capita consumption in the EU (71.2 liters in average). Market analysts frequently distinguish carbonated soft drinks or sodas - colas, tonics, carbonated fruit drinks, lemonade - and uncarbonated soft drinks - iced tea, fruits drinks. In France, carbonated soft drinks represent $78.5 \%$ of the market and uncarbonated soft drinks $21.5 \%$ in 2004. The three main categories are colas ( $54 \%$ of all soft drinks), fruit drinks ( $25 \%$ for both carbonated and non carbonated products) and iced tea (8\%). Soft drinks do not include fruit juices and nectars which represent a significant part of beverage consumption. Those products do not contain a significant proportion of added sugar and they are thus not directly concerned by the change in sugar price. ${ }^{7}$ In our analysis, they are included in the 'outside' option for consumers as they are substitute of soft drinks.

In general, there are two versions of each soft drink: a regular one which is sweetened using caloric sweeteners, almost exclusively sugar in France, and a diet one which is sweetened using non-caloric sweeteners such as aspartame or acesulfame. The two main ingredients of regular soft drinks are water (about 90\%) and sweetener (about 10\%). The main ingredient of a diet soft drink is water (99.7\%). Obviously, soft drinks also contain food additives such as food coloring, artificial flavoring, emulsifiers and preservatives.

\section{Data}

We use data from a consumer panel data collected by TNS WordPanel. We have a french representative survey of 19,000 households over a three years period (2003-2005). This survey provides information on purchases of food products (quantity, price, brand, characteristics of goods, store) and on characteristics of households (income, number of children and adults, weight and height of each person, ...).

According to our sample, the average total consumption of regular soft drinks per year and per person is lower when households have no overweight and obese individuals. Indeed, consumption amounts to

\footnotetext{
${ }^{6}$ Note that the consumption of diet drinks increased by $224 \%$ from 1994 to 2004 . Nevertheless, their market share is still lower than $20 \%$.

${ }^{7}$ Fruit juices do not contain added sugar while nectar contains less than $6 \%$ of added sugar.
} 
32 liters per year and per person in those households while it is 34 liters for households where some individuals are overweight or obese. ${ }^{8}$ When all members of the household are overweight or obese, the consumption rise to 37 liters per year and per person and 41 liters if all members are obese.

From the panel data, we select the 11 main national brands (NB) of the soft drink industry and three private labels (PL), one for each of the three categories of products (colas, iced tea, fruit drinks). We select the nine largest retailers in France. Taking into account the set of products distributed by each retailer we get 105 (or 104 depending on the period) differentiated products which compete on the market. ${ }^{9}$

Market shares are defined as follows. The relevant market is the whole market of SSBs including soft drinks, fruit juice and nectar. Then, market share of a given brand in a given retailer is defined as the ratio of the sum of purchases of the brand in the selected retailer during a period of four weeks and the sum of purchases of all brands in all retailers in the relevant market during the same period. In this setting, the outside option (which represents $66 \%$ of the whole market) is composed of two elements: purchases of fruit juice and nectar (40\% of the market) on the one hand and purchases of non selected soft drinks or non selected retailers on the other hand. ${ }^{10}$

Table I: General Descriptive Statistics for Prices and Market Shares

\begin{tabular}{lcc}
\hline \hline & $\begin{array}{c}\text { Prices (in euros per liter) } \\
\text { Mean (std) }\end{array}$ & $\begin{array}{c}\text { Market Shares } \\
\text { Mean in \% }\end{array}$ \\
\hline \hline Outside Good & & 66.2 \\
Soft Drinks & $0.82(0.25)$ & 33.8 \\
\hline Regular products & $0.78(0.26)$ & 80.8 \\
Diet products & $0.92(0.16)$ & 19.2 \\
\hline National brands & $0.93(0.153)$ & 73.1 \\
Private labels & $0.47(0.13)$ & 26.9 \\
\hline \hline
\end{tabular}

Selected soft drinks account for $33.8 \%$ of the whole market (Table I). The average price over products and periods is 0.82 euros per liter. Regular products dominate the market as they represent about $80 \%$

\footnotetext{
${ }^{8}$ These figures are lower than the figure previously cited in section 2 because they only consider at home consumption.

${ }^{9}$ From the consumer perspective, a product is the combination of a brand and a retailer. We account for this precise differentiation because prices differ by retailer. Moreover, the sugar content of private labels also varies across retailers.

${ }^{10}$ We exclude 77 brands as well as 66 retailers or distribution channels. All those only represent $27 \%$ of the market.
} 
of soft drinks purchases; their prices are $15 \%$ lower than those of diet products. PLs hold about $27 \%$ of the market of soft drinks and are sold at about half of the price of NBs. Those products also differ by their sugar content (Figure 1). Indeed, the sugar content is 0 for diet products and varies from 56 to $110 \mathrm{~g}$ per liter for regular brands.

Figure 1: Distribution of sugar content of soft Drink products

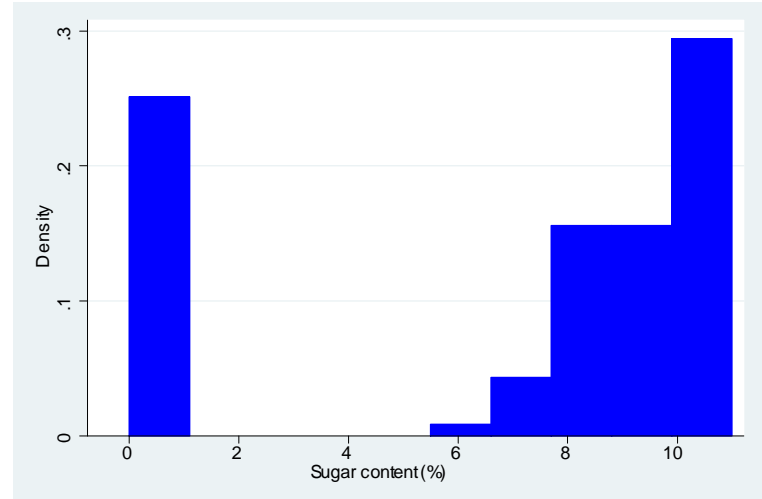

\section{The Demand Model: a random-coefficients logit model}

To get price elasticities of demand for every differentiated product we need a demand model as flexible as possible and thus opt for a random-coefficients logit model (Berry et al., 1995; McFadden and Train, 2000). This model is based on a random utility specification that takes into account the observed and unobserved heterogeneity in consumers' preferences. Moreover, this discrete choice model allows to account for the product differentiation in an easy way since it allows to project the large number of products on a space of characteristics (McFadden, 1973).

The indirect utility funtion $V_{i j t}$ for the consumer $i$ buying the product $j$ at period $t$ is given by

$$
V_{i j t}=\beta_{j}+\gamma_{t}-\alpha_{i} p_{j t}+\rho_{i} l_{j}+\xi_{j t}+\varepsilon_{i j t}
$$

where $\beta_{j}$ are product fixed effects which capture the (time invariant) unobserved product characteristics, $\gamma_{t}$ are time fixed effects (dummies) which capture time demand shocks, $p_{j t}$ is the price of the 
product $j$ at period $t$ and $\alpha_{i}$ the marginal disutility of price for consumer $i, l_{j}$ is a dummy related to an observed product characteristic (which takes 1 if the product $j$ is a diet product and 0 otherwise) and $\rho_{i}$ captures consumer $i$ 's taste for the diet characteristic, $\xi_{j t}$ captures the unobserved variation in the product characteristics and $\varepsilon_{i j t}$ is an unobserved individual-specific error term.

We assume that $\alpha_{i}$ and $\rho_{i}$ vary across consumers. Indeed, consumers may have a different price disutility or different tastes for the diet characteristic. We assume their distributions are independent and parameters have the following specification:

$$
\left(\begin{array}{c}
\alpha_{i} \\
\rho_{i}
\end{array}\right)=\left(\begin{array}{c}
\alpha \\
\rho
\end{array}\right)+\Pi D_{i}+\Sigma v_{i}
$$

where $D_{i}$ is a $d \times 1$ vector of demographics and $v_{i}=\left(v_{i}^{\alpha}, v_{i}^{\rho}\right)^{\prime}$ a $2 \mathrm{x} 1$ vector which captures the unobserved consumers characteristics. $\Pi$ is a $2 \times d$ matrix of coefficients that measure the taste characteristics through demographics and $\Sigma$ is a $2 \times 2$ diagonal matrix of parameters $\left(\sigma_{\alpha}, \sigma_{\rho}\right)$ that measure the unobserved heterogeneity of consumers. We suppose that $P_{v}($.$) is a parametric distribution of v_{i}, P_{D}($.$) is a$ non parametric distribution known from data and $D_{i}$ and $v_{i}$ are independant. This specification allows demographics to affect taste characteristics, reducing the reliance on parametric assumptions.

We can break down the indirect utility in a mean utility $\delta_{j t}=\beta_{j}+\gamma_{t}+\alpha p_{j t}+\rho l_{j}+\xi_{j t}$ and a deviation to this mean utility $\mu_{i j t}=\left[p_{j t}, l_{j}\right]\left(\sigma_{\alpha} v_{i}^{\alpha}+\pi_{\alpha} D_{i}, \sigma_{\rho} v_{i}^{\rho}+\pi_{\rho} D_{i}\right)^{\prime}$. The indirect utility is given by $V_{i j t}=\delta_{j t}+\mu_{i j t}+\varepsilon_{i j t}$.

The consumer may decide not to choose one of the products considered. Thus, we introduce an outside option allowing for substitution between the considered products and a substitute. The utility of this outside good is normalized to zero. The indirect utility of choosing the outside good is $V_{i 0 t}=\varepsilon_{i 0 t}$.

Assuming that $\varepsilon_{i j t}$ is independently and identically distributed like an extreme value type I distribution, we are able to write the market share of product $j$ at period $t$ in the following way (Nevo, 2001):

$$
s_{j t}=\int_{A_{j t}}\left(\frac{\exp \left(\delta_{j t}+\mu_{i j t}\right)}{1+\sum_{k=1}^{J_{t}} \exp \left(\delta_{k t}+\mu_{i k t}\right)}\right) d P_{\nu}(\nu) d P_{D}(D)
$$

where $A_{j t}$ is the set of consumers who have the highest utility for product $j$ at period $t$, a consumer is defined by the vector $\left(D_{i}, \nu_{i}, \varepsilon_{i 0 t}, \ldots, \varepsilon_{i J t}\right)$. We assume that the distribution $P_{\nu}$ follows an independant 
bivariate normal distribution with means $\alpha$ and $\rho$ and standard deviations $\sigma_{\alpha}$ and $\sigma_{\rho}$ of $v_{i}^{\alpha}$ and $v_{i}^{\rho}$ respectiveley.

The random-coefficients logit model generates a flexible pattern of substitutions between products driven by the different consumer price disutilities $\alpha_{i}$. Thus, the own and cross-price elasticities of the market share $s_{j t}$ can be written as:

$$
\frac{\partial s_{j t}}{\partial p_{k t}} \frac{p_{k t}}{s_{j t}}=\left\{\begin{array}{cl}
-\frac{p_{j t}}{s_{j t}} \int \alpha_{i} s_{i j t}\left(1-s_{i j t}\right) \phi\left(v_{i}\right) d v_{i} & \text { if } j=k \\
\frac{p_{k t}}{s_{j t}} \int \alpha_{i} s_{i j t} s_{i k t} \phi\left(v_{i}\right) d v_{i} & \text { otherwise. }
\end{array}\right.
$$

\section{Results}

In this section, we present and discuss demand results as well as the results of the policy simulation.

\subsection{Demand results}

We estimate the random coefficients logit model using the well-known GMM method proposed by Berry et al. (1995) and Nevo $(2000,2001)$. This method requires the use of a set of instruments to solve the endogeneity problem of prices. We use input price indexes of wages, plastic, aluminium, sugar and gazole as it is unlikely that input prices are correlated with unobserved demand determinants. ${ }^{11}$ These variables are interacted with manufacturers dummies because we expect that manufacturers obtain from suppliers different prices for raw materials and the quality of plastic and aluminium may changed over manufacturers.

Table II shows results of the demand model estimates by GMM accounting for consumer heterogeneity in the sensitivity of price and the taste of observed product characteristics. ${ }^{12}$ First, note that the overidentifying restriction test is not rejected meaning that instruments are valid. On average, the price has a significant and negative impact on utility. The proportion of overweight and obese individuals in a household affects positively the price coefficient meaning that these households are less price sensitive. Proportion of obese in the household does not significantly influence the price sentivity of households. Futhermore, the coefficient of the dummy identifying diet products is negative on average meaning that

\footnotetext{
${ }^{11}$ These indexes are from the French National Institute for Statistics and Economic Studies.

${ }^{12}$ This estimation was realized with 500 draws for the parametric distribution representing the unobserved consumer characteristics and the nonparametric distribution of consumer demographics.
} 
consumers do not like this characteristic. However, the standard deviation is large meaning that some consumers like diet products and some others do not like them. The proportion of overweight and obese individuals and the proportion of obese individuals have no impact on the coefficient of the diet characteristic.

Table II: Results for the random coefficients logit model

\begin{tabular}{lcc}
\hline \hline Coefficients (Std. error) & Mean & Standard Deviation \\
& & \\
\hline \hline Price & $-8.55(1.57)$ & $2.52(0.95)$ \\
$\quad$ Proportion of overweight and obese people & $6.50(1.92)$ & \\
$\quad$ Proportion of obese people & $-6.32(7.02)$ & \\
Diet & $-0.72(0.08)$ & $2.20(0.86)$ \\
$\quad$ Proportion of overweight and obese people & $2.72(2.63)$ & \\
$\quad$ Proportion of obese people & $4.93(3.71)$ & \\
Coefficients $\delta_{j}, \gamma_{t}$ not shown & & \\
Overidentifying Restriction Test (df) & $26.11(17)$ & \\
\hline \hline
\end{tabular}

From the structural demand estimates, we are able to compute own and cross-price elasticities for each differentiated products (Table III). ${ }^{13}$ Own-price elasticities of demand for a brand vary between -2.92 and -4.37 and is -3.93 on average. Our results suggest that demand for regular products is slightly less elastic than demand for diet products (diet products are brands 2, 4, 6 and 9). Thus, own-price elasticity of demand for regular brands is about -3.87 while it is about -4.08 for diet brands, these means are statistically different. Finally, PL demand is less price elastic than NB demand. Same magnitude of own-price elasticities are obtained by other studies on the soft drink markets in the US, specially if one takes into account the way brands are defined. Obviously, price elasticity of demand for a 'product' does depend on the definition of the product. A priori, the more brands are distinguished in the analysis the higher the elasticity of a single brand. Thus, Gasmi et al. (1992) estimated own-price elasticities to -2 for Coca-Cola and Pepsi-Cola. For the Carbonated Soft Drink US market, Dhar et al. (2005) distinguished 4 brands and found own-price elasticities between -2 and -4 . On the same market, but using a higher level of disagregation (about 20 brands), Dubé (2005) found elasticities ranging from -3 to $-6^{14}$.

\footnotetext{
${ }^{13}$ To built this table we compute the elasticities of brands within each retailer and we report the average over the different retailers of each elasticity and overtime.

${ }^{14}$ Unfortunately, according to our knowledge, there is no other study on the French soft drink market.
} 
The analysis of cross-price elasticities among products in a given retailer reveals that substitutions are mainly among products with similar sugar profile, that is regular products (that is sweetened with caloric sweeteners) substitute with other regular products rather than with a diet product. Conversely, diet products substitute more with the other diet products than they do with regular products. The taste category (cola, ice tea, fruit drinks) does not seem to play a significant role in the substitutions as substitution within a taste category are not larger than between categories.

Finally, we are able to compute the own price elasticities for households with different demographic characteristics. As a consequence of the positive coefficient of price for the proportion of overweight and obese people in an household, we find average own price elasticities varying from -5.49 to -3.14 when the proportion of overweight and obese individuals in the household increases. Then, household with overweight and obese people will react less to a change in the price of brand. The decrease of regular product prices in response to the foreseen decrease in sugar price is likely to induce a larger (in percent) increase in the consumption of soft drink by household without overweight and obese people than by household with .

Table III: Own and Cross Price Elasticities between Brands within the same Retailer

\begin{tabular}{|c|c|c|c|c|c|c|c|c|c|c|c|c|c|c|}
\hline & Brand 1 & B rand 2 & Brand 3 & Brand 4 & Brand 5 & Brand 6 & Brand 7 & Brand 8 & Brand 9 & Brand 10 & Brand11 & Brand12 & Brand 13 & Brand 14 \\
\hline Sugar & $\mathrm{R}$ & $\mathrm{D}$ & $\mathrm{R}$ & D & $\mathrm{R}$ & $\mathrm{D}$ & $\mathrm{R}$ & $\mathrm{R}$ & $\mathrm{D}$ & $\mathrm{R}$ & $\mathrm{R}$ & $\mathrm{R}$ & $\mathrm{R}$ & $\mathrm{R}$ \\
\hline Categ. & 1 & 1 & 1 & 1 & 2 & 2 & 3 & 3 & 3 & 3 & 3 & 1 & 2 & 3 \\
\hline Brand1 & -4.2078 & 0.0029 & 0.0044 & 0.0019 & 0.0040 & 0.0016 & 0.0041 & 0.0038 & 0.0017 & 0.0045 & 0.0044 & 0.0063 & 0.0062 & 0.0062 \\
\hline Brand 2 & 0.0049 & -4.3676 & 0.0043 & 0.0358 & 0.0039 & 0.0268 & 0.0040 & 0.0037 & 0.0289 & 0.0043 & 0.0043 & 0.0047 & 0.0046 & 0.0046 \\
\hline Brand 3 & 0.1303 & 0.0531 & -4.1961 & 0.0563 & 0.1274 & 0.0524 & 0.1291 & 0.1217 & 0.0545 & 0.1339 & 0.1336 & 0.0965 & 0.1132 & 0.1084 \\
\hline Brand 4 & 0.0348 & 0.2791 & 0.0361 & -4.0739 & 0.0352 & 0.1958 & 0.0356 & 0.0344 & 0.2084 & 0.0358 & 0.0360 & 0.0261 & 0.0298 & 0.0288 \\
\hline Brand5 & 0.0161 & 0.0066 & 0.0173 & 0.0074 & -4.0720 & 0.0072 & 0.0175 & 0.0170 & 0.0075 & 0.0172 & 0.0173 & 0.0103 & 0.0130 & 0.0119 \\
\hline Brand 6 & 0.0022 & 0.0147 & 0.0024 & 0.0138 & 0.0025 & -3.8166 & 0.0025 & 0.0025 & 0.0126 & 0.0024 & 0.0024 & 0.0014 & 0.0018 & 0.0016 \\
\hline Brand 7 & 0.0155 & 0.0063 & 0.0166 & 0.0071 & 0.0165 & 0.0068 & -4.0960 & 0.0161 & 0.0071 & 0.0165 & 0.0166 & 0.0102 & 0.0128 & 0.0118 \\
\hline Brand 8 & 0.0150 & 0.0061 & 0.0164 & 0.0072 & 0.0168 & 0.0071 & 0.0169 & -3.8687 & 0.0073 & 0.0163 & 0.0165 & 0.0090 & 0.0117 & 0.0106 \\
\hline Brand 9 & 0.0074 & 0.0507 & 0.0079 & 0.0465 & 0.0081 & 0.0398 & 0.0082 & 0.0081 & -4.0222 & 0.0079 & 0.0080 & 0.0049 & 0.0059 & 0.0055 \\
\hline Brand 10 & 0.0171 & 0.0070 & 0.0176 & 0.0073 & 0.0165 & 0.0068 & 0.0167 & 0.0158 & 0.0071 & -4.3028 & 0.0174 & 0.0132 & 0.0150 & 0.0143 \\
\hline Brand11 & 0.0101 & 0.0041 & 0.0105 & 0.0044 & 0.0100 & 0.0041 & 0.0101 & 0.0096 & 0.0043 & 0.0104 & -4.2762 & 0.0072 & 0.0087 & 0.0082 \\
\hline Brand 12 & 0.0112 & 0.0052 & 0.0054 & 0.0023 & 0.0040 & 0.0017 & 0.0044 & 0.0037 & 0.0019 & 0.0054 & 0.0052 & -2.9243 & 0.0119 & 0.0119 \\
\hline Brand 13 & 0.0084 & 0.0037 & 0.0063 & 0.0026 & 0.0053 & 0.0021 & 0.0055 & 0.0048 & 0.0023 & 0.0063 & 0.0062 & 0.0096 & -3.6356 & 0.0091 \\
\hline Brand 14 & 0.0184 & 0.0081 & 0.0146 & 0.0060 & 0.0119 & 0.0048 & 0.0125 & 0.0108 & 0.0052 & 0.0147 & 0.0142 & 0.0199 & 0.0190 & -3.4884 \\
\hline
\end{tabular}

R means regular; D means diet 


\subsection{Simulation of the sugar policy reform}

In line with the anticipated impact of the reform of the EU sugar policy, we simulate a $36 \%$ decrease in the sugar price. Using the sugar content of each product, we calculate the decrease in cost due to the price cut of sugar. In average, the decrease of sugar price generates a decrease in the production cost of $2 €$ cents for regular products. Depending on the sugar content, the decrease varies from 1.79 to $2.68 €$ cents (see Table IV). Assuming a full transmission of the production cost decrease to the final price, consumer prices of regular products decrease by more than $3.4 \%$ in average. Price changes are heterogenous (from $-1.7 \%$ to $-6.5 \%)$ as both cost reduction and initial prices are different among products. In particular, as PLs are priced about $50 \%$ lower than NBs, the percent decrease in PL price is higher.

\subsubsection{Impact on market shares}

Decrease in prices of regular products lead to an increase in the aggregate market share of regular products by $7.5 \%$. This is due to substitution with diet products (whose market share decreases by $3.5 \%$ ) as well as with the outside option (whose market share decreases by $3 \%$ ). ${ }^{15}$ We find that changes in market share are very heterogeneous across brands (Table IV). Private labels as well as brands 1 and 3 manage to get the larger increases. This result suggests that taking into account the differentiation of products in a food category is important. In particular, it is interesting to note that among NBs it is brands with the highest sugar content which increase most their market share. PLs also increase significantly their market shares. In average they have a lower sugar content but their composition is not homogenous as PLs are different from one retailer to another one. It is also worth noting that when market share are evaluated in points (rather than in \%) it is brand 3 which increases most its market share. Brand 3 has a 'high' sugar content. Thus, not only there is substitution between regular and diet products but also among regular products there is substitution at the benefit of products with the highest sugar content.

\footnotetext{
${ }^{15}$ It should be acknowledged that the price of the outside option is assumed to be unchanged which is a limit in the analysis. However, a significant part of the goods in the outside option will not be affected by the decrease in the sugar price as those goods do not contain any added sugar.
} 
Table IV: Simulation of a decrease by one third decrease of the sugar price

\begin{tabular}{l|c|c|c|c|c}
\hline \hline & $\begin{array}{c}\text { Sugar Content } \\
\text { in grams per liter) } \\
\text { Mean (std) }\end{array}$ & $\begin{array}{c}\text { Change in cost } \\
(€ \text { cents) } \\
\text { Mean (std) }\end{array}$ & $\begin{array}{c}\text { Change in price } \\
(\%) \\
\text { Mean (std) }\end{array}$ & $\begin{array}{c}\text { Change in MS } \\
\text { (points) } \\
\text { Mean (std) }\end{array}$ & $\begin{array}{c}\text { Change in MS } \\
(\%) \\
\text { Mean (std) }\end{array}$ \\
\hline \hline Brand 1 & $110()$. & $2.68(0.05)$ & $-3.69(0.50)$ & $+0.09(0.01)$ & $10.25(1.85)$ \\
Brand 2 & - & - & - & $-0.03(0.01)$ & $-3.74(0.50)$ \\
Brand 3 & $103()$. & $2.58(0.05)$ & $-2.94(0.16)$ & $+0.77(0.06)$ & $7.32(0.93)$ \\
Brand 4 & - & - & - & $-0.15(0.02)$ & $-3.59(0.50)$ \\
Brand 5 & $73.6(0.36)$ & $1.79(0.12)$ & $-1.73(0.14)$ & $0.02(0.01)$ & $1.93(0.73)$ \\
Brand 6 & - & - & - & $-0.01(0.00)$ & $-3.12(0.72)$ \\
Brand 7 & $90()$. & $2.19(0.04)$ & $-2.16(0.23)$ & $0.04(0.01)$ & $3.77(1.05)$ \\
Brand 8 & $105()$. & $2.55(0.05)$ & $-2.28(0.16)$ & $0.05(0.01)$ & $4.23(0.92)$ \\
Brand 9 & - & - & - & $-0.03(0.01)$ & $-3.34(0.56)$ \\
Brand 10 & $92()$. & $2.24(0.04)$ & $-2.61(0.21)$ & $0.08(0.02)$ & $5.73(0.94)$ \\
Brand 11 & $102()$. & $2.48(0.05)$ & $-2.75(0.25)$ & $0.05(0.01)$ & $6.43(1.30)$ \\
Brand 12 & $95(15)$ & $2.32(0.39)$ & $-6.55(2.00)$ & $0.52(0.04)$ & $14.60(4.30)$ \\
Brand 13 & $76(27)$ & $1.86(0.07)$ & $-3.69(1.00)$ & $0.17(0.04)$ & $7.78(1.58)$ \\
Brand 14 & $89(59)$ & $2.16(0.15)$ & $-4.52(0.83)$ & $0.45(0.06)$ & $10.84(1.63)$ \\
\hline \hline
\end{tabular}

\subsubsection{Impact on households}

Thanks to the demand estimate which takes into account different price sensitivities according to the obesity status of the household, we are able to recover the change in the average consumption of different groups of households. Table V provides the increase in average consumption of regular and diet products as well as the increase in the consumption of added sugar for 3 groups of households.

The average consumption of regular products increases by 1.16 liters while the average consumption of diet products remains roughly identical. Consumption of added sugar would raise by 124 grams per person and per year. However, the presence of overweight or obese individuals in the household plays a role. For households where less than half of the members are overweight and obese, the increase is about 1.3 liters of regular soft drinks and 141 grams of added sugar, which are statistically different from the results of an average household.

We estimated the increase in added sugar consumption using two methods. The first one takes into account the true sugar content of each brand (fifth column). The second one assumes an average sugar content (sixth column). The first estimate is in average 5\% higher than the second (from $4 \%$ to $6 \%$ depending on households). Thus anything else constant (in particular the change in market share of each brand), the substitution in favour of brands with a high content of sugar increases by $5 \%$ the change in 
added sugar consumption.

Table V: Change in consumption for different groups of households (liter or gram/person/year)

\begin{tabular}{l|c|c|c|cc}
\hline \hline $\begin{array}{l}\text { Percentage of } \\
\text { overweight and } \\
\text { obese households }\end{array}$ & $\begin{array}{c}\text { Proportion of } \\
\text { households } \\
(\%)\end{array}$ & $\begin{array}{c}\text { Regular Soft Drinks } \\
\text { Mean (std) } \\
(\mathrm{l} / \mathrm{p} / \text { year })\end{array}$ & $\begin{array}{c}\text { Diet Soft Drinks } \\
\text { Mean (std) } \\
(\mathrm{l} / \mathrm{p} / \text { year })\end{array}$ & $\begin{array}{c}\text { Added Sugar } \\
\text { Differentiated (1) } \\
\text { (g/p/year) }\end{array}$ & $\begin{array}{c}\text { Added Sugar } \\
\text { Average(2) } \\
(\mathrm{g} / \mathrm{p} / \text { year) }\end{array}$ \\
\hline \hline No & 44 & $1.19(0.06)$ & $-0.00(0.00)$ & 116 & 112 \\
less than half & 35 & $1.42(0.08)$ & $-0.03(0.01)$ & 141 & 116 \\
More than half & 21 & $1.16(0.10)$ & $-0.47(0.06)$ & 124 & 109 \\
\hline Total Population & 100 & $1.16(0.07)$ & $-0.11(0.01)$ & 118 \\
\hline \hline
\end{tabular}

(1): Taking into account the sugar content of each brand (2) Using an average content

\section{Conclusion}

The reform of the EU sugar policy reform will induce a significant decrease in the price of sugar. This reform is at odds of what is recommended by health authorities which in order to combat obesity call for a decrease in the consumption of added sugar. To anticipate the impact of the sugar policy reform on added sugar consumption we focused our analysis on a specific sector, the soft drink industry which is frequently denunciated as a significant contributor to the obesity problem. We argue that such impact analysis should take into account the existence of numerous and highly differentiated products in the food market. Using a very flexible demand model, we are able to simulate the impact on soft drink consumption of the recent EU reform of the sugar market. Our results suggest that 1) the decrease by $36 \%$ of the sugar price might induce an increase in the consumption of regular soft drinks by $7.5 \%$ while the consumption of diet products would be slightly reduced 2) the decrease in sugar price not only increases the aggregate market share of regular soft drinks but it also favors products with the highest sugar content; the increase in added sugar consumption is thus due to the increase in consumption of soft drinks and to the substitution between brands in favor of the most sweetened. 3) the larger the proportion of overweight and obese individuals in a household, the less sensitive to change in prices consumers are; as households with a higher proportion of overweight and obese people have a larger initial consumption of soft drinks, the change in consumption among households is less variable than the initial consumption. 
In this analysis we have considered that cost reduction is fully transmitted to consumer prices. This implicitly assumes marginal cost pricing through the vertical chain. Depending on how costs changes are transmitted to the final prices, this might lead to over or under estimate the impact of the reform. In France, Campa and Golberg (2006) showed that the retail price transmission is greater than 1 in the food retailing industry. According to this result, assuming a 1 to 1 cost price transmission leads to underestimate the impact of the reform.

The quantitative changes in sugar consumption might be considered as small or even neglictible. We argue it is not the case for two reasons. First, it should be acknowledged that the SSB consumption in France is lower than in Europe. For example, the SSBs consumption in UK is larger than $100 \mathrm{l} /$ person/year which is 2.5 times the consumption in France. As the sugar policy reform apply to all EU countries, in countries like UK, the impact on sugar added consumption is likely to be significantly higher. Second the refom of the sugar policy will affect all sweet products market while here we focused on a specific market. Then the impact on consumption of added sugar is likely to be larger. In any case, from a health perspective, the reform goes in the wrong direction.

Finally, if one considers that SSBs plays a significant role on the epidemic of obesity, our results suggest that taxing SSBs could help combatting obesity. Thus, consumption reacts significantly to prices. Our results also suggest that the tax should be set in relation to the sugar content in order to avoid substitution in favor of products with high sugar contents.

\section{References:}

AFSSA. 2009. Etude individuelle nationale des consommations alimentaires 2 (INCA2, 2006-2007). http://www.afssa.fr/Documents/PASER-Ra-INCA2.pdf.

Allais O, P Bertail, V Nichele. 2010. The effects of a Fat Tax on French Households' Purchases: a Nutritional Approach. American Journal of Agricultural Economics 92: 228-245.

Alston JM, Sumner DA, Vosti SA. 2006. Are Agricultural Policies Making Us Fat? Likely Links between Agricultural Policies and Human Nutrition and Obesity, and Their Policy Implications. Review 
of Agricultural Economics 28(3): 313-322

Beghin J, el Osta B, Cherlow J, Mohanty S 2003. The Cost of the U.S. Sugar program Revisited, Contemporary Economic Policy 21(1): 106-116.

Berry S, Levinsohn J, Pakes A. 1995. Automobile Prices in Market Equilibrium, Econometrica 63: $841-890$

Bonnet C, Dubois P, Orozco V. 2009. Food consumption and obesity in France: identification of causal effects and price elasticities, Toulouse School of Economics

Campa JM, Goldberg LS. 2006. Pass Through of Exchange Rates to Consumption Prices: What has Changed and Why?, NBER Working Papers 12547.

Canadean. 2004. website http://www.canadean.com/

Chouinard H, Davis D, LaFrance J, Perloff J. 2007. Fat Taxes: Big Money for Small Change." Forum for Health Economics and Policy 10: Iss. 2 (Obesity), Article 2.

http://www.bepress.com/fhep/10/2/2.

Cooper J, Giraud-Héraud E, Réquillart V. 1995. Economic Impacts of Isoglucose Deregulation on the European Sweetener Market, European Review of Agricultural Economics 22(4): 425-445.

Cutler DM, Glaeser EL, Shapiro JM. 2003. Why have americans become more obese? Journal of Economic Perspectives 17(3): 93-118.

Dhar T, Chavas, JP, Cotterill RW, Gould BW. 2005. An Economeric Analysis of Brand-Level Strategic Pricing Between Cocal-Cola Company and Pepsico, Journal of Economics and Management Strategy 14(4): 905-931

Dube JP. 2005. Product Differentiation and Mergers in the Carbonated Soft Drink Industry, Journal of Economics and Management Strategy 14(4): 879-904

Etile F. 2010. Food Prices and BMI: Theory and Empirical Evidence from France. mimeo

European Commission. 2004. A description of the Common Organization of the Market in Sugar. Agriculture Directorate-general, AGRI/63362/2004.

Gasmi F, Laffont JJ, Vuong Q. 1992. Econometric Analysis of Collusive Behavior in a Soft-Drink 
Market, Journal of Economics and Management Strategy 1(2), 277-311.

Harnack L, Stang J, Story M. 1999. Soft Drink Consumption among US children and adolescents: nutritional consequences, Journal of the American Dietetic Association 99(4), 436-441

Jacobson MF, Brownell KD. 2000. Small taxes on soft drinks and snack foods to promote health. American Journal of Public Health 90: 854-857

Leicester A, F Windmeijer. 2004. The 'Fat Tax': Economic Incentives to Reduce Obesity. IFS Briefing Note 49: June 2004

Lloyd-Williams F, O'Flaherty M, Mwatsama M, Birt C, Ireland R, Capewell S. 2008. Estimating the cardiovascular mortality burden attributable to the EuropeanCommon Agricultural Policy on dietary saturated fats. Bulletin of the World Health Organization 86(7): 535-542.

Ludwig DS, Peterson KE, GortmakerSL. 2001. Relation between consumption of sugar-sweetened drinks and childhood obesity: a prospective, observational analysis. The Lancet 357(February 17): 505508.

Malik VS, Shulze MB, Hu FB. 2006. Intake of sugar-sweetened beverages and weight gain: a systematic review. American Journal of Clinical Nutrition 84: 274-288.

Marshall T. 2000. Exploring a Fiscal Food Policy: the Case of Diet and Ischaemic Heart Disease. British Medical Journal320: 301-305.

Mazzochi M, Traill WB, Shogren JF. 2009. Fat Economics: Nutrition, Health, and Economic Policy. Oxford University Press.

McFadden D. 1973. Conditional Logit Analysis of Qualitative Choice Behavior, in P. Zarembka, ed., Frontiers of Economics, New York: Academy Press

McFadden D, Train K. 2000. Mixed MNL Models for discrete Response, Journal of applied Econometrics 15(5), 447-470

Melanson KJ, Zukley L, Lowndes J, Nguyen V, Angelopoupos TJ, Rippe JM. 2007. Effects of highfructose corn syrup and sucrose consumption on circulating glucose, insulin, leptin and ghrelin and on appetite in normal-weight women. Nutrition 23: 103-112. 
Ministère de la Santé et des Solidarités 2006. Deuxième Programme national nutrition santé, - 20062010 -. Actions et mesures. http://www.sante.gouv.fr/htm/actu/pnns_060906/plan.pdf

Nevo A. 2000. Mergers with Differentiated Products: the Case of the Ready-to-Eat Cereal Industry, RAND Journal of Economics 31, 395-421.

Nevo A. 2001. Measuring Market Power in the Ready-To-Eat Cereal Industry, Econometrica, 69: $307-342$.

Ransley JK, Donnelly JK, Botham H, Khara TN, Greenwood DC, Cade JE. 2003. Use of supermarket receipts to estimate energy and fat content of food purchased by lean and overweight families. Appetite 41: $141-148$

Sassi F, Devaux M, Cecchini M, Rusticelli E. 2009. The obesity epidemic: analysis of past and projected future trends in selected OECD countries. OECD Health Working Papers, $\mathrm{n}^{\circ} .45$

Smed S, J Jensen,S Denver. 2007. Socio Economic Characteristics and the effect of taxation as a Health Policy Instrument. Food Policy 32: 624-639.

Schroeter C, Lusk J, Tyner W. 2008. Determining the impact of food price and income changes on body weight. Journal of Health Economics 27: 45-68.

Union Européenne. 2006., Règlement (CE) n 318/2006 du Conseil du 20 février 2006 portant organisation commune des marchés dans le secteur du sucre, Journal officiel n L 058 du 28/02/2006 p. 0001 $-0031$. 